\begin{tabular}{|l|l|}
$\begin{array}{l}\text { Postprint } \\
\text { Version }\end{array}$ & 1.0 \\
\hline Journal website & http://informahealthcare.com/doi/abs/10.3109/14767058.2013.798289 \\
\hline Pubmed link & $\underline{\text { http://www.ncbi.nlm.nih.gov/pubmed/23611721 }}$ \\
\hline DOI & $10.3109 / 14767058.2013 .798289$ \\
\hline
\end{tabular}

This is a NIVEL certified Post Print, more info at http://www.nivel.eu

\title{
Determinants affecting pregnant women's utilization of prenatal screening for Down syndrome: a review of the literature
}

\author{
Neeltje M. Crombag ${ }^{1}$, Jozien M. Bensing ${ }^{2}$, Rita Iedema-Kuiper ${ }^{1}$, Peter C. SChielen ${ }^{3}$, \\ AND GERARD H. VISSER ${ }^{1}$ \\ ${ }^{1}$ University Medical Centre Utrecht, Department of Obstetrics, Utrecht, The Netherlands, \\ ${ }^{2}$ The Netherlands Institute for Health Services Research, Utrecht, The Netherlands, and \\ ${ }^{3}$ National Institute for Public Health and the Environment, Diagnostic Laboratory for \\ Infectious Diseases and Perinatal Screening, Bilthoven, The Netherlands
}

\begin{abstract}
Objective: Uptake rates for Down syndrome screening (DSS) in the Netherlands are low compared with those in Northern European countries (27\% versus $61 \%$ in the United Kingdom and $90 \%$ in Denmark). These differences are unexpected, especially since the countries have similar cultural and social values.

Method: To analyse factors that underlie differences in uptake we reviewed current literature on individual characteristics and healthcare system factors, which determine potential influential factors on utilization of DSS.

Results: Arguments “'Against abortion”' and “Down syndrome (DS) not severe enough condition to terminate pregnancy" correlated with declining DSS, whereas "Perceived guidance of healthcare professional," "'Perceived negative attitude of society towards DS" and "Preparation/ Early termination" correlated with accepting DSS. However, the majority of determinants were used both in favour of accepting or declining DSS.

Conclusions: Decision making regarding DSS seems a process with influences on different levels and subtle interactions rather than a dichotomous process. Utilization may also be influenced by the implicit way it is being offered, as an extra option or as part of routine care and how this offer is perceived by the social environment. Finally, national healthcare system characteristics, although underrepresented in the examined studies, may also influence participation in DSS.
\end{abstract}




\section{INTRODUCTION}

Down syndrome screening (DSS) is performed in the first trimester of pregnancy by maternal serum screening and by ultrasound measurement of the fetal nuchal translucency. Its aim is to inform prospective parents on the risk of Down syndrome (DS) in the ongoing pregnancy, to provide them with timely options, including invasive diagnostic procedures in case of an increased risk for DS, and, if diagnosed for DS, preparation for a disabled child or termination of pregnancy (TOP) [1]. In the Netherlands, DSS is offered to all pregnant women. Accepting or declining should be an informed and autonomous choice as consequences of a screen positive result and knowledge about the condition might lead to complex ethical, emotional and social dilemmas. Therefore, the choice should be based on accurate and balanced information and in concordance with the client's attitude and values [2].

Uptake rates of DSS in the Netherlands are low compared to those of other Northern European countries (27\% versus 61\% in the UK and 90\% in Denmark [3-7]). As these countries show close resemblance regarding social and cultural factors, have an extensive screening program and are comparable both in content, execution and basic values of informed and autonomous choice, these findings are unexpected [8-11].

\section{[FIGURE 1] [ TABLE 1]}

Preceding a larger study on those factors that underlie the differences in uptake, this article aims to study the current literature on factors that affect participation in DSS, including individual characteristics and healthcare characteristics, and their mutual interaction.

A general framework to study differences in uptake is the Andersen Model of Health Care Utilization (Figure 1). This model suggests that people's use of health services is a function of their predisposition to use services, factors which enable or impede use, and their need for care. The predisposing characteristics are subcategorized in demographic, social and health beliefs factors. Demographic factors represent the biological imperatives people need to use health services. Social structure represents factors that determine the status of a person in the community, the ability to cope with problems and to command resources to deal with these problems, such as existing social network, social interaction and culture. Health beliefs stand for attitudes, beliefs and knowledge that people have on health and health service and that might influence their subsequent perceptions of need and use of healthcare services. The enabling or impeding factors consist of health system characteristics (availability of facilities and healthcare personnel), organizational characteristics (accessibility of health services, waiting time), financial factors (health insurance and reimbursement) and personal factors (means and knowledge to access and use services, travel time). Need factors can be classified in perceived and evaluated need. Perceived need represents the imperative that accounts for personal care-seeking, consumption of services and adherence to a medical regimen while evaluated need represents professional judgement of health status [12].

To our best knowledge, a narrative review of the literature integrating the effect of both the individual and healthcare characteristics on uptake has not been published before. Therefore, we searched the literature on studies that reported determinants of influence on screening behaviour and classified these determinants according to the Andersen model. The purpose of this study was to answer the following question: 
- Which are the individual and environmental factors (predisposing, enabling and need), known from the current literature that correlate with participation in DSS?

\section{METHOD}

\section{Literature research}

We have identified full text articles on studies in the peer-reviewed literature in English regarding determinants of influence on utilization of prenatal screening for DS. Studies were obtained from a search in Medline, Embase and PsycINFO from January 1990 up to March 2012. The starting date corresponded with the introduction of the first DSS program in the early nineties. The syntax is listed in Table 1.

Inclusion criteria:

- Participants included pregnant women, or women with a history of past pregnancy

- Participants regarded participation in prenatal screening

- Studies which described factors of influence on decline or acceptance of prenatal screening

- Both qualitative and quantitative studies

- Studies that considered pregnant women's views

- Studies from Western countries

- Studies describing prenatal diagnosis, TOP, expert opin- ions or the supply side were excluded.

\section{Mixed method}

We explicitly chose a mixed method approach, integrating both quantitative and qualitative studies. The analysis of quantitative data provides a general understanding of the research problem and a representative picture of the situation, while the analyses of qualitative data complement and refine those statistical results by exploring participants' views in more depth. Synthesis of either qualitative or quantitative data alone may obscure factors that are potentially important in altering the uptake $[13,14]$. The conclusions of a review can be substantially altered by the inclusion of qualitative data, which are more likely to reflect the experiences of the target group [15].

\section{[TABLE 2]}

For quantitative studies significant results were collected, for qualitative studies we collected author's findings and created relevant themes. Subsequently, the results of the studies were grouped according to the Andersen classification as perceived by pregnant women. Finally, the results were categorized in major topics and subdivided into qualitative or quantitative results. 
Crombag, N.M., Bensing, J.M., ledema-Kuiper, R., Schielen, P.C., Visser, G.H. Determinants affecting pregnant women's utilization of prenatal screening for Down syndrome: a review of the literature. Journal of Maternal-Fetal and Neonatal Medicine: 2013, 26(17), 1676-1681

\section{RESULTS}

\section{Studies included}

The literature search (Table 1) identified 422 publications. Study of the title showed that 124 of these met the inclusion criteria. Screening the abstracts of these publications revealed that 52 abstracts met all the inclusion criteria and were assessed for the full publication. Thirteen studies of the 422 met all inclusion criteria. These are listed in Supplementary table. Five studies had a quantitative design, and eight had a qualitative design.

The results were categorized according to their effect on acceptance or decline of DSS. The subdivision is summarized in Table 2. A description per subcategory is given below.

\section{Decline}

\section{Predisposing}

Health beliefs and social factors were the categories mentioned most often as influential in declining DSS. Health beliefs could be subdivided into attitudes towards DS, disability, abortion, nature and experience. Women who declined DSS weighed the possibilities of an adverse screening result in relation to their moral beliefs and values [16]. Women with most favourable attitudes towards people with DS were the least likely to intend to test and terminate [17]. In both qualitative and quantitative studies, women mentioned that DS was a condition, not severe enough to terminate pregnancy [18-23].

The qualitative data showed a more in depth explanation of women's values and beliefs. The attributed value to life with a disability, and their expected ability to cope emotionally with a disabled child, were important reasons for declining [20]. The moral authority of nature, in which nature has to take its course and whereby having a healthy or handicapped child is destiny, has been mentioned in qualitative studies as a reason to decline $[18,20]$. Frequently mentioned reasons to decline were “'being against abortion" or "'not wanting to have an abortion," and were found in qualitative as well as in quantitative studies [22,23]. Qualitative data illustrated that views on abortion were directly related to screening choices, showing that women who were reluctant to consider termination, did not consider participating in DSS [22]. Personal experience with DS and DSS was associated with either being in favour or against testing [18,23,24]. In both qualitative and quantitative studies, negative experiences of friends with prenatal testing, such as stress and grief $[19,23,24]$, particularly with false positive results, influenced women towards declining DSS. Test decliners more often lacked embodied knowledge (e.g. they had not experienced serious illnesses themselves, nor were they aware of illness in their families), and therefore, presumed that DSS was unnecessary [23].

Decliners acknowledged that all parents want a healthy child but at the same time felt that variability and complexity in ability and health should be maintained in society. Besides, they felt the need to defend their decision towards society [18].

\section{Enabling}

Determinants categorized as enabling factors concerned mainly organizational factors.

Unfavourable characteristics, for example, unreliability of the test, and adverse characteristics of a possible subsequent invasive test, were mentioned as reasons to 
decline DSS, both in qualitative and quantitative studies [18,22]. In quantitative studies, practical reasons, such as unsuitable visiting hours for test performance, were also reported to influence the utilization of DSS [19].

\section{Need}

Unjust anxiety or uncertainty, due to possible false positive results, were frequently mentioned as reasons to decline DSS, both in qualitative and quantitative studies $[19,20,22]$. Additionally, in qualitative studies, decliners considered avoiding unnecessary risks for the fetus as the most rational action in the best interest of the child [20]. A number of women declined because testing was perceived as not applicable (e.g. 'II am too young') [22].

\section{Accept}

Predisposing. The determinants of accepting DSS can be roughly divided into two categories; health beliefs and social factors. The attitude towards DS or parenting a child with DS, was directly related to accepting DSS. Almost all women holding a negative attitude towards parenting a child with DS tended to accept screening [17]. In both qualitative and quantitative data, screening was accepted without direct association with abortion, but as a step towards further diagnosis $[17,20]$. The qualitative data gave a more detailed explanation of attitudes. Women mentioned their "philosophy of life" as the determining factor in the decision to have DSS [24]. Although a disabled child might help family members to cope with adversity and to appreciate the value of little and irrelevant things, the expected unbearable emotional and physical burden of a child with DS had been decisive in accepting testing [20]. However, for some acceptors the attitudes towards disability were not always based on knowledge, but were a reflection of their wish for a healthy baby [25].

Acceptors considered testing as a possibility to control nature and to interfere with the pregnancy outcome in order to guarantee a good life for themselves and their children. This attitude was only found in qualitative data $[20,24]$. Professional experience with children with DS could become a factor either in favour or against testing [23]. Women with personal experience, from close associations with others, on raising a child with DS, had vividly anticipated a life with a child with a disability. These women chose testing to be prepared or have the option to terminate [23].

With regards to the external environment of pregnant women, qualitative studies have reported that women who accepted screening more often mentioned guidance from their healthcare professional. Perceived negative attitude of society towards DS or social discrimination have also been mentioned as influencing factors on accepting DSS [21,25].

Enabling. The enabling factors could be subdivided into financial and organisational factors.

In qualitative studies the financial burden of a child with DS has been mentioned as a reason to accept testing, especially by prospective fathers $[16,25]$. Quantitative and qualitative data showed that favourable characteristics and technical advances of the screening test were also factors in accepting testing [16,19,22,25].

Need. Need factors could be divided into objective need and subjective need. A priori increased risk for DS (e.g. advanced maternal age) is frequently considered as 
a medical reason to perform a screening test ("objective need"), and therefore, mentioned as a reason why women decide to accept testing [22]. For some women accepting testing was a self-evident act, and considered as part of routine care. This was confirmed in both qualitative and quantitative, studies [19,25]. Among the subjective or personal need factors,

"seeking reassurance," “'hope for a healthy baby" and

"reduction of anxiety" were often mentioned as reasons to accept DSS, both in qualitative and quantitative studies [17,19,20,23,25]. The possibility to prepare in case of a determined disability and to terminate early were also reported reasons to accept $[16,19,23]$. In addition, a number of women mentioned becoming knowledgeable or curious [22]. Best interest of the child, and ensuring a good life for their child (prevention of life with a major disability) were other reasons to accept testing [20].

\section{Discussion}

In this review, determinants of influence on uptake of DSS, as perceived by pregnant women were studied according to their effect on participation (Table 2). We categorized the deter- minants according to the Andersen model of Health Care Utilization, thus covering factors at the individual and at the health system level. Our results indicate that the factors "Against abortion"' and "DS not severe enough condition to terminate preg- nancy" correlated with declining whereas " perceived guid- ance of healthcare professional," " "perceived negative attitude of society towards DS" and " preparation/early termination'” correlated with accepting DSS [16,19-23,25]. Most factors mentioned by decliners could be categorized as predisposing (dominated by health beliefs). Decliners often had strong personal opinions, which hardly seem to be influenced by the guidance of health professionals or existing enabling factors in the healthcare system. Acceptors also relied on predisposing factors, but their attitudes were socially more diverse.

In contrast to the identified differences, we were also able to identify nine major similarities in arguments concerning participation in screening. Our results indicate that " "nature," " "attitude towards DS,", " experience," “'supportive influence of others," “"test characteristics,", “'reassurance,” “'anxiety,” "best interest of the child" and "participation"' were mentioned both in favour of and against screening. They comprised predisposing, need and enabling factors. By including both qualitative and quantitative studies we were able to complement, confirm and refine the statistical results. "Perceived negative attitude of society," "perceived guidance from healthcare professionals," " "nature" and "best interest of the child" were factors extracted from qualitative data alone and may be a more specific explanation of the wish to reduce anxiety and seek reassurance $[19,22,25]$. First, we can conclude that both women accepting and those declining refer to the same factors to support their choice (Table 3), which has also been mentioned by others $[20,22,26]$. A possible explanation is that the process of decision making, particularly with regard to ethical, emo- tional and social dilemma's, is not a rational and dichotomous process. Perhaps, decisions on DSS are made on different levels, reflected in predisposing and need factors, and are justified on rational grounds (need and enabling). Women decide on prenatal testing by balancing the information provided by the test against the risk of further investigation, the emotional burden of a disabled child on their well-being and their life perspective, as well as that of 
family members. Normative moral principles are introduced when the choice is made, namely, as factors justifying and supporting the decision [20].

As consequences of a screen positive result and knowledge about the condition emerge complex ethical, emotional and social dilemmas, informed decision making remains import- ant, but one should realize that women might use the information to justify their intuitive choice, rather than making a choice after non-directive counseling. The finding that the majority of women (60-70\%) decide before consultation could also be a reflection of this $[27,28]$.

The emphasize of "healthcare beliefs" factors affecting utilization is in line with previous studies on women's reasons for participation in DSS which have shown relationships between attitudes (health beliefs) and actual testing behaviour [2,17,2730]. A recent Dutch study demonstrated that a relatively positive attitude toward DS and a negative attitude toward TOP were related to the low uptake in this country. Most women would not consider TOP in case of a diagnosed DS [30]. Healthcare beliefs (attitudes and values) remain useful in explaining the individual use of healthcare, but cannot explain the large differences in uptake between Northern European countries. The existing uptake differences suggest correlations not only with individual characteristics, such as health beliefs and need, but also with healthcare system characteristics and their mutual interaction. Therefore, second, we conclude that system characteristics, such as (perceived) enabling or impeding factors (e.g. universal offer, reimbursement, informed choice), which are underexposed in literature, could be of influence on national participation in DSS. In the included studies, DSS is formally offered in an opt-in fashion. In practice, utilization may be influenced by the implicit way it is offered, as an extra option or as part of routine care. Moreover, it may not be directly influenced by the way it is offered, but rather by how utilization is perceived by the social environment. The moral significance of prenatal testing is inseparably bounded by the social context in which it is practiced. This effect of national healthcare policies has not been addressed before.

The effect of both individual and healthcare characteristics on utilization of DSS has not been extensively studied and this article summarizes the available data for the first time. Due to low number of studies, originating from only five countries, the general applicability of the study results may be limited. Restriction to English language studies could have excluded locally published studies on influential factors in European countries. The mixed method approach strengthens the findings of this study, as the more general results were confirmed and broadened by the more specific results of the qualitative studies.

In conclusion, with this review we suggest that decision making regarding DSS is rather a subtle process of influences on different levels than a dichotomous process. Decision making might be justified later, on rational grounds. Another factor of influence might be whether it is offered as an option or as part of routine care. Future research should focus on the subtle process of decision making and on the influence and role of different levels. Moreover, more research is needed on the influence of healthcare system characteristics, such as enabling and impeding factors, and on the mutual interaction of these factors.

\section{[TABLE 3]}


Crombag, N.M., Bensing, J.M., ledema-Kuiper, R., Schielen, P.C., Visser, G.H. Determinants affecting pregnant women's utilization of prenatal screening for Down syndrome: a review of the literature. Journal of Maternal-Fetal and Neonatal Medicine: 2013, 26(17), 1676-1681

\section{Declaration of interest}

The author is supported by foundation of Friends of the UMC Utrecht (UMC Utrecht grant organisation).

\section{REFERENCES}

1. Gezondheidsraad. Wet bevolkingsonderzoek: prenatale screening op downsyndroom en neurale buisdefecten(Health Counsil of The Netherlands Population Screening Act:

Prenatal screening for Down's syndrome and neural tube defects); 2007. Report no. 2007/05WBO.

2. Marteau TM, Dormandy E, Michie S. A measure of informed choice. Health Expect 2001;4:99-108.

3. Ekelund CK, Andersen HJ, Christensen J, et al. Down's syndrome risk assessment in Denmark-secondary publication. Ugeskr Laeger

2010;172:1759-61.

4. Ekelund CK, Jorgensen FS, Petersen OB, et al. Danish Fetal Medicine Research Group. Impact of a new national screening policy for Down's syndrome in Denmark: population based cohort study. Br Med J 2008;337:a2547.

5. Ekelund CK, Petersen OB, Skibsted L, et al. First-trimester screening for trisomy 21 in Denmark: implications for detection and birth rates of trisomy 18 and trisomy 13. Ultrasound Obstet Gynecol 2011;38:140-44.

6. Ward P. Down's syndrome screening in England. Committee UNS 2011.

7. Schielen PC. Quality control parameters of the Dutch Down syndrome screening Laboratories 2010 National Institute for Public Health and the Environment, Diagnostic Laboratory for Infectious Diseases and Perinatal Screening The Netherlands; 2011.

8. Boyd PA, Devigan C, Khoshnood B, et al. Survey of prenatal screening policies in Europe for structural malformations and chromosome anomalies, and their impact on detection and termin- ation rates for neural tube defects and Down's syndrome. BJOG 2008;115:689-96.

9. van den Heuvel A, Chitty L, Dormandy E, et al. Is informed choice in prenatal testing universally valued? A population-based survey in Europe and Asia. BJOG 2009;116:88085.

10. van den Heuvel A, Chitty L, Dormandy E, et al. Informed choice in prenatal testing: a survey among obstetricians and gynaecologists in Europe and Asia. Prenat Diagn 2008;28:1238-44.

11. Hall S, Chitty L, Dormandy E, et al. Undergoing prenatal screening for Down's syndrome: presentation of choice and information in Europe and Asia. Eur J Hum Genet 2007;15:56369.

12. Andersen RM. Revisiting the behavioral model and access to medical care: does it matter? J Health Soc Behav 1995;36:1-10.

13. Roberts KA, Dixon-Woods M, Fitzpatrick R, et al. Factors affecting uptake of childhood immunisation: a Bayesian synthesis of qualitative and quantitative evidence. Lancet 2002; 360:1596-99.

14. Creswell JW, Plano Clark VL. Choosing a mixed methods design. In: Designing and conducting mixed methods research. 2nd ed, Chapter 3. Thousand Oaks: SAGE publications; 2011:104.

15. Thomas J, Harden A, Oakley A, et al. Integrating qualitative research with trials in systematic reviews. Br Med J 2004;328: 1010-12.

16. Williams C, Sandall J, Lewando-Hundt G, et al. Women as moral pioneers? Experiences of first trimester antenatal screening. Soc Sci Med 2005;61:1983-92.

17. Bryant LD, Green JM, Hewison J. The role of attitudes towards the targets of behaviour in predicting and informing prenatal testing choices. Psychol Health 2009;25:1175-94.

18. Gottfredsdottir H, Bjornsdottir K, Sandall J. How do prospective parents who decline prenatal screening account for their decision? A qualitative study. Soc Sci Med 2009;69:274-77.

19. Santalahti P, Hemminki E, Latikka AM, Ryynanen M. Women's decision-making in prenatal screening. Soc Sci Med 1998;46: 1067-76. 
Crombag, N.M., Bensing, J.M., ledema-Kuiper, R., Schielen, P.C., Visser, G.H. Determinants affecting pregnant women's utilization of prenatal screening for Down syndrome: a review of the literature. Journal of Maternal-Fetal and Neonatal Medicine: 2013, 26(17), 1676-1681

20. Garcia E, Timmermans DR, van Leeuwen E. The impact of ethical beliefs on decisions about prenatal screening tests: searching for justification. Soc Sci Med 2008;66:753-64.

21. Garcia E, Timmermans DRM, Van Leeuwen E. Rethinking autonomy in the context of prenatal screening decision-making. Prenat Diagn 2008;28:115-20.

22. van den Berg M, Timmermans DR, Kleinveld JH, et al. Accepting or declining the offer of prenatal screening for congenital defects: test uptake and women's reasons. Prenat Diagn 2005;25:84-90.

23. Etchegary $\mathrm{H}$, Potter $\mathrm{B}$, Howley $\mathrm{H}$, et al. The influence of experiential knowledge on prenatal screening and testing decisions. Genet Test 2008;12:115-24.

24. Carroll JC, Brown JB, Reid AJ, Pugh P. Women's experience of maternal serum screening. Can Fam Physician 2000;46:614-20.

25. Gottfredsdottir H, Sandall J, Bjornsdottir K. 'This is just what you do when you are pregnant': a qualitative study of prospective parents in Iceland who accept nuchal translucency screening. Midwifery 2009;25:711-20.

26. Reid B, Sinclair M, Barr O, et al. A meta-synthesis of pregnant women's decision-making processes with regard to antenatal screening for Down syndrome. Soc Sci Med 2009;69:1561-73.

27. van den Berg M, Timmermans DR, Kleinveld JH, et al. Are counsellors' attitudes influencing pregnant women's attitudes and decisions on prenatal screening? Prenat Diagn 2007;27:518-24.

28. Bakker M, Birnie E, Pajkrt E, et al. Low uptake of the combined test in the Netherlands which factors contribute? Prenat Diagn 2012;32:1305-12.

29. Michie S, Dormandy E, Marteau TM. The multi-dimensional measure of informed choice: a validation study. Patient Educ Couns 2002;48:87-91.

30. St-Jacques S, Grenier S, Charland M, et al. Decisional needs assessment regarding Down syndrome prenatal testing: a systematic review of the perceptions of women, their partners and health professionals. Prenat Diagn 2008;28:1183-203.

\section{FIGURE AND TABLES}

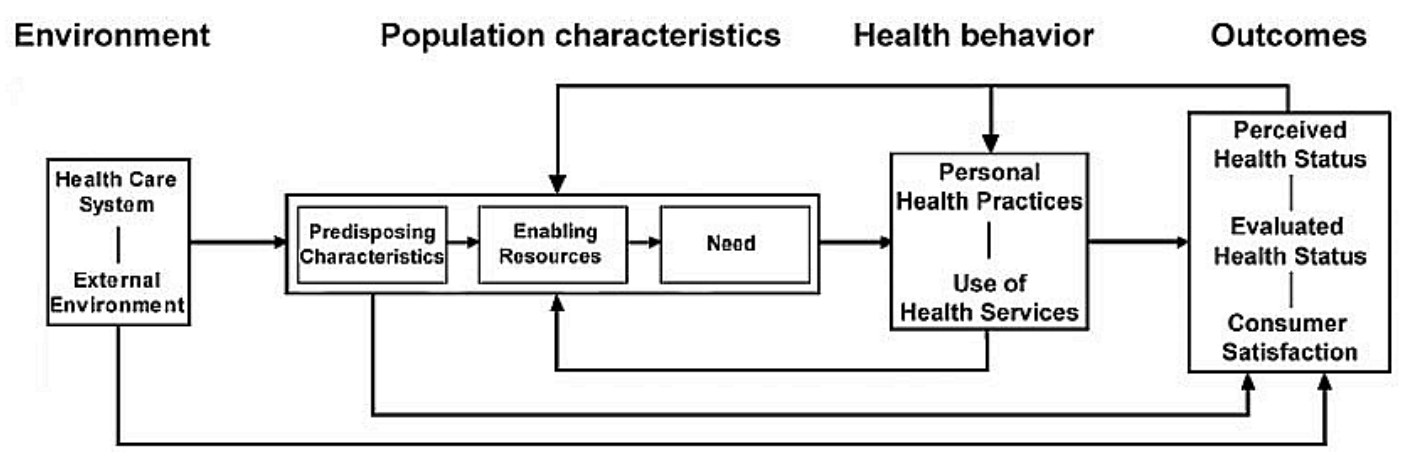

Figure 1. The Andersen model of health behaviour [12]. Reprinted with permission from the American Sociological Association. 
Crombag, N.M., Bensing, J.M., ledema-Kuiper, R., Schielen, P.C., Visser, G.H. Determinants affecting pregnant women's utilization of prenatal screening for Down syndrome: a review of the literature. Journal of Maternal-Fetal and Neonatal Medicine: 2013, 26(17), 1676-1681

Table 1. Search syntax.

Search syntax

Topic Prenatal screening OR Prenatal testing OR Maternal serum screening OR Nuchal translucency measurement OR Antenatal screening OR Antenatal testing OR Antenatal care OR Prenatal care OR Down's syndrome screening OR Down syndrome screening OR Screening tests OR Prenatal counselling OR Prenatal counselling AND Down syndrome OR Down OR Downs OR Down's OR Trisomy 21 OR Aneuploidy

Theme Determinants OR Variables OR Factors OR Reasons OR Decisional needs OR Attitudes OR Informed choice OR Non-directiveness OR Nondirectiveness OR Autonomous choice OR Emotions OR External constraints OR Internal constraints OR Moral beliefs OR Moral justification OR Ethics OR Uptake OR Screening uptake OR Participation OR Decline OR Accept OR Decision-making OR Decision making OR Utilization OR Use

Table 2. Association of major topics found in the included studies, grouped according to the Andersen model, subdivided in qualitative and quantitative studies and on utilization of prenatal screening for Down's syndrome (i.e. accept versus decline).

\begin{tabular}{|c|c|c|c|c|}
\hline \multirow[b]{2}{*}{ Topic } & \multicolumn{2}{|c|}{ Decline } & \multicolumn{2}{|c|}{ Accept } \\
\hline & Qualitative & Quantitative & Qualitative & Quantitative \\
\hline \multicolumn{5}{|l|}{ Predisposing } \\
\hline Against abortion & $\begin{array}{l}\text { Etchegary 2008, Garcia } \\
2008\end{array}$ & $\begin{array}{c}\text { Van de Berg 2005, } \\
\text { Santalahti } 1998\end{array}$ & & \\
\hline $\begin{array}{l}\text { DS not being severe enough } \\
\text { to terminate pregnancy }\end{array}$ & $\begin{array}{l}\text { Gottfredsdottir 2009, } \\
\text { Garcia } 2008\end{array}$ & Santalahti 1998 & & \\
\hline Attitudes, beliefs and values & $\begin{array}{l}\text { Williams 2005, Caroll } \\
\text { 2000, Garcia 2008, } \\
\text { Gottfredsdottir 2009 }\end{array}$ & Santalahti 1998 & $\begin{array}{l}\text { Caroll } 2000, \\
\text { Gottfredsdottir 2009, } \\
\text { Garcia } 2008\end{array}$ & Bryant 2009 \\
\hline Nature & Garcia 2008, Caroll 2000 & & Garcia 2008 & \\
\hline Experience & $\begin{array}{l}\text { Etchegary 2008, Caroll } \\
2000 \text {, Gottfredsdottir } \\
2009\end{array}$ & Santalahti 1998 & $\begin{array}{l}\text { Etchegary 2008, Caroll } \\
\quad 2000\end{array}$ & \\
\hline $\begin{array}{l}\text { Perceived guidance from } \\
\text { healthcare professionals }\end{array}$ & & & Gottfredsdottir 2009 & \\
\hline $\begin{array}{l}\text { Perceived negative attitudes } \\
\text { of society towards DS }\end{array}$ & & & Gottfredsdottir 2009 & \\
\hline $\begin{array}{l}\text { Supportive influence of } \\
\text { significant others }\end{array}$ & $\begin{array}{l}\text { Caroll 2000, Garcia 2008, } \\
\text { Williams 2005, } \\
\text { Gottfredsdottir } 2009\end{array}$ & Park 2009 & $\begin{array}{l}\text { Caroll 2000, Garcia } \\
\text { 2008, Williams 2005, } \\
\text { Gottfredsdottir 2009 }\end{array}$ & Park 2009 \\
\hline \multicolumn{5}{|l|}{ Enabling } \\
\hline Test characteristics & Gottfredsdottir 2009 & $\begin{array}{c}\text { Van de Berg 2005, } \\
\text { Santalahti } 1998\end{array}$ & $\begin{array}{l}\text { Williams 2005, } \\
\text { Gottfredsdottir } 2009\end{array}$ & $\begin{array}{r}\text { Van de Berg 2005, } \\
\text { Santalahti } 1998\end{array}$ \\
\hline $\begin{array}{l}\text { Need } \\
\text { Reassurance }\end{array}$ & & Van de Berg 2005 & $\begin{array}{l}\text { Etchegary 2008, } \\
\quad \text { Gottfredsdottir } 2009\end{array}$ & Santalahti 1998 \\
\hline Anxiety & Garcia 2008 & $\begin{array}{c}\text { Van de Berg 2005, } \\
\text { Santalahti } 1998\end{array}$ & Garcia 2008 & Van de Berg 2005 \\
\hline Part of routine care & & & Gottfredsdottir 2009 & Santalahti 1998 \\
\hline Abortion/prepare & & & $\begin{array}{l}\text { Williams 2005, } \\
\text { Etchegary } 2008\end{array}$ & Santalahti 1998 \\
\hline
\end{tabular}


Crombag, N.M., Bensing, J.M., ledema-Kuiper, R., Schielen, P.C., Visser, G.H. Determinants affecting pregnant women's utilization of prenatal screening for Down syndrome: a review of the literature. Journal of Maternal-Fetal and Neonatal Medicine: 2013, 26(17), 1676-1681

nive

Table 3. Differences and similarities between arguments against or in favour regarding the utilization of prenatal screening for Down's syndrome, grouped according to the Andersen model and subdivided in qualitative and quantitative studies.

\begin{tabular}{|c|c|c|c|c|}
\hline \multirow[b]{2}{*}{ Topic } & \multicolumn{2}{|c|}{ Decline } & \multicolumn{2}{|c|}{ Accept } \\
\hline & Qualitative & Quantitative & Qualitative & Quantitative \\
\hline \multicolumn{5}{|l|}{ Differences } \\
\hline Against abortion & + & + & - & - \\
\hline DS not being severe enough to terminate pregnancy & + & + & - & - \\
\hline Perceived guidance from healthcare professionals & - & - & + & - \\
\hline Perceived negative attitudes of society towards DS & - & - & + & - \\
\hline Abortion/prepare & - & - & + & + \\
\hline \multicolumn{5}{|l|}{ Similarities } \\
\hline Attitudes, beliefs and values & + & + & + & + \\
\hline Participation & - & + & + & + \\
\hline Nature & + & - & + & - \\
\hline Experience & + & + & + & - \\
\hline Supportive influence of significant others & + & + & + & + \\
\hline Test characteristics & + & + & + & + \\
\hline Reassurance & - & + & + & + \\
\hline Anxiety & + & + & + & + \\
\hline Best interest of the child & + & - & + & - \\
\hline
\end{tabular}

